\title{
Vitamin D status, dietary intake, and bone turnover in female Soldiers during military training: a longitudinal study
}

\author{
Laura J Lutz ${ }^{1}$, J Philip Karl ${ }^{1}$, Jennifer C Rood ${ }^{2}$, Sonya J Cable ${ }^{3}$, Kelly W Williams ${ }^{3}$,
}

Andrew J Young ${ }^{1}$ and James P McClung ${ }^{1 *}$

\begin{abstract}
Background: Vitamin $D$ is an essential nutrient for maintaining bone health, to include protecting against stress fracture during periods of rapid bone turnover. The objective of this longitudinal, observational study was to assess vitamin D status, biomarkers of bone turnover, and vitamin $D$ and calcium intake in female Soldiers $(n=91)$ during US Army basic combat training (BCT).

Methods: Anthropometric, biological and dietary intake data were collected at wk 0, 3, 6, and 9 of the 10 wk BCT course. Mixed models repeated measures ANOVAs were used to assess main effects of time, race, and time-by-race interactions.

Results: White volunteers experienced a decrease in serum 25(OH)D levels, whereas non-white volunteers experienced an increase during BCT. However, serum 25(OH)D levels were lower in non-whites than whites at all timepoints (P-interaction $<0.05$ ). Group mean PTH levels increased $(P<0.05)$ during the first 3 wk of training, remained elevated for the duration of $\mathrm{BCT}$, and were higher in non-whites compared to whites (P-race $<0.05$ ). Biomarkers of both bone formation (bone alkaline phosphatase and procollagen I N-terminal peptide) and resorption (tartrate-resistant acid phosphatase and $C$-terminal telopeptide) increased $(P<0.05)$ during $B C T$, indicating increased bone turnover. Estimated daily intakes of vitamin $\mathrm{D}$ and calcium were below recommended levels $(15 \mu \mathrm{g}$ and $1000 \mathrm{mg} /$ day, respectively), both before (group mean \pm SEM; $3.9 \mu \mathrm{g} / \mathrm{d} \pm 0.4$ and $887 \mathrm{mg} / \mathrm{d} \pm 67$ ) and during BCT $(4.1 \mu \mathrm{g} / \mathrm{d} \pm 0.3$ and $882 \mathrm{mg} / \mathrm{d} \pm 51)$.
\end{abstract}

Conclusions: These findings demonstrate that female Soldiers experience dynamic changes in vitamin D status coupled with increased bone turnover and potentially inadequate vitamin D and calcium intake during military training.

Keywords: Vitamin D, Calcium, Parathyroid hormone, Bone turnover, Soldiers

\section{Background}

Vitamin D is an essential nutrient for the maintenance of human health and performance. Various biological roles have been described for vitamin $\mathrm{D}$, including cardiac, immune, and musculoskeletal functions $[1,2]$. Perhaps the best described function of vitamin $\mathrm{D}$ is as an endocrine regulator of calcium homeostasis. The biologically active form of vitamin D, 1,25-dihydroxyvitamin

\footnotetext{
*Correspondence: James.McClung3@us.army.mil

${ }^{1}$ Military Nutrition Division, United States Army Research Institute of Environmental Medicine, Natick, MA 01760, USA

Full list of author information is available at the end of the article
}

D $\left(1,25(\mathrm{OH})_{2} \mathrm{D}\right)$, affects intestinal calcium absorption by inducing the synthesis of the calcium transport protein calbindin [3]. Low $1,25(\mathrm{OH})_{2} \mathrm{D}$ levels diminish intestinal calcium absorption and induce parathyroid hormone (PTH) secretion. PTH stimulates resorption of calcium from bone in an effort to maintain serum calcium levels [4]. Diminished vitamin D status may degrade bone health, and has been associated with osteomalacia in adults [5], and low bone mineral content (BMC) and bone mineral density (BMD) in children and adults [6].

Poor vitamin D status may increase stress fracture risk $[7,8]$. Stress fractures are more prevalent in females than 
males. It has been estimated that up to $20 \%$ of female athletes and military personnel may experience a stress fracture during training [9]. Suboptimal vitamin D status (assessed using serum 25-hydroxyvitamin D (25(OH)D levels) may contribute, as military training may affect biomarkers of both bone formation and resorption [10], and declines in serum $(25(\mathrm{OH}) \mathrm{D})$ levels have been observed in female personnel undergoing military training [11]. Further, supplementation with $20 \mu \mathrm{g}$ of vitamin $\mathrm{D}$ in conjunction with $2000 \mathrm{mg}$ of calcium reportedly reduced stress fracture incidence in female Navy recruits [12].

Despite observations of diminished serum 25(OH)D levels during military training, and the elevated risk of stress fracture in female military personnel [13], no study has comprehensively assessed the effects of military training on serum $25(\mathrm{OH}) \mathrm{D}$, PTH levels and biochemical indices of bone turnover in female Soldiers. Similarly, dietary intake of vitamin D and calcium have not been assessed during military training. As such, the objective of this longitudinal, observational study was to assess the effects of US Army basic combat training (BCT) on serum 25(OH)D, PTH levels, bone turnover, and vitamin D and calcium intake in female Soldiers. Effects of race on outcome measures were also assessed, as racial differences in serum $25(\mathrm{OH}) \mathrm{D}$ levels have been described previously by our group [11] and others $[14,15]$. We hypothesized that vitamin D status would improve in Soldiers training during the early spring months in the Southeastern US, as solar load increases in this location during the early spring, and that indicators of both bone formation and resorption would be increased in response to the physical activity experienced during military training.

\section{Methods}

\section{Participants}

This study was approved by the Human Use Review Committee at the United States (US) Army Research Institute of Environmental Medicine and was conducted at Fort Jackson, SC between the months of February and April. Human volunteers participated in this study after giving their free and informed consent. Investigators adhered to US Army Regulation 70-25 and US Army Medical Research and Material Command regulation $70-25$ on the participation of volunteers in research.

The data provided in this report were collected as a part of a larger study assessing cardiometabolic risk in military recruits [16]. A total of 91 female Soldiers consented to participate in the present study. Body composition and demographic data were collected within one wk of the start (baseline) and completion (wk 9) of BCT. Hematological data were collected at four timepoints through BCT; at baseline and wk 3, 6, and 9. A total of
71 female Soldiers were included in the statistical analysis; volunteers were excluded from statistical analysis if they withdrew from the study, separated from the Army or their baseline or wk 9 data were missing. Demographic characteristics of the volunteers appear in Table 1.

\section{Basic combat training}

The BCT course is the initial exposure to military training for individuals who enlist in the US Army. It is a 910 wk course that consists of both outdoor and indoor classroom training [17]. However, during most portions of the training, Soldiers wear combat uniforms which allow exposure of only the hands, neck, and face to the sun. Physical training is conducted outdoors and is comprised of aerobic (i.e., road marching, navigating obstacle courses, and running) and strength-training activities (i.e., calisthenics, push-ups, and sit-ups). The BCT course typically results in increased ambulatory activity; previously collected data regarding energy expenditure during $\mathrm{BCT}$ have been reported elsewhere [18].

The feeding environment at $\mathrm{BCT}$ consists of ad libitum cafeteria-style meals for breakfast, lunch, and dinner. Foods offered meet military dietary reference intakes (MDRIs) [19], which are similar to the DRIs for the American population, but adjusted for the specific needs of the military. Food offererings at military dining facilities aim to provide a well balanced diet and meet the Dietary Guidelines for Americans [19].

\section{Anthropometric measures}

Weight was measured and recorded to the nearest $0.01 \mathrm{~kg}$ on a calibrated digital scale (A\&A Scales, Prospect Park, NJ), and height was measured to the nearest $0.01 \mathrm{~cm}$ with a stadiometer (Creative Health Products, Plymouth, MI). Body fat percentages were estimated from skinfold thicknesses. Skinfold measurements were recorded using Lange calipers (Beta Technology, Santa

Table 1 Female volunteer characteristics at baseline*

\begin{tabular}{lccr}
\hline & $\begin{array}{c}\text { Group } \\
(\mathbf{n}=\mathbf{7 1})\end{array}$ & $\begin{array}{c}\text { White } \\
(\mathbf{n}=\mathbf{4 5})\end{array}$ & $\begin{array}{c}\text { Non-white } \\
(\mathbf{n}=\mathbf{2 6})\end{array}$ \\
\hline Age, $\mathrm{yr}$ & $23.1 \pm 0.7$ & $23.5 \pm 1.0$ & $22.4 \pm 0.9$ \\
\hline Height, $\mathrm{cm}$ & $162.7 \pm 0.7$ & $163.1 \pm 0.8$ & $162.2 \pm 1.3$ \\
\hline Weight, $\mathrm{kg}$ & $66.1 \pm 1.0$ & $64.9 \pm 1.3$ & $68.1 \pm 1.4$ \\
\hline BMl, $\mathrm{kg} / \mathrm{m}^{2}$ & $24.9 \pm 0.3$ & $24.4 \pm 0.4$ & $25.9 \pm 0.4 \dagger$ \\
\hline Body Fat, $\%$ & $26.6 \pm 0.7$ & $25.2 \pm 0.8$ & $28.9 \pm 1.0$ \\
\hline Race, $\mathrm{n}$ & & & \\
\hline White or Caucasian & 45 & & \\
\hline Black or African American & 18 & \\
\hline Asian & 1 & & \\
\hline Other & 7 & \\
\hline
\end{tabular}

* Mean \pm SEM; † Different from white $(P<0.05)$. 
Cruz, CA) at the triceps, suprailiac, and abodominal sites, and were rounded to the nearest $1.0 \mathrm{~mm}$. Body density was calculated according to the 3-site skinfold equation for women [20], and body fat percentage was then determined using sex-, age-, and race-specific calculations [21].

\section{Biological samples}

After an overnight fast, blood was collected from rested volunteers through antecubital venipuncture, processed on site, frozen, and shipped to the Pennington Biomedical Research Center (Baton Rouge, LA) for processing. Serum 25(OH)D levels (DiaSorin Inc., Stillwater, $\mathrm{MN}$ ) were determined using a commercially available radioimmunoassay and PTH levels (Siemens 2000, Los Angeles, CA) were determined using a commercially available immunoassay. Serum bone alkaline phosphatase (BAP; Octeia, Fountain Hills, AZ), procollagen I N-terminal peptide (PINP; Orion Diagnostica, Espoo, Finland), tartrate-resistant acid phosphatase (TRAP; Immunodiagnostics Systems, Fountain Hills, AZ), and C-terminal telopeptide (CTx; Immunodiagnostics Systems, Fountain Hills, AZ) were determined using immunoassays. Serum IL-6 concentrations were determined using a multiplex assay with a lower detectible limit of 3.2 ng/L (Milliplex MAP; Millipore, Billerica, MA) and high-sensitivity C-reactive protein (hsCRP) concentrations were determined with an automated immunoassay instrument with a lower detectible limit of $0.2 \mathrm{mg} / \mathrm{L}$ (Siemens Medical Solutions USA, Inc.).

\section{Dietary intake}

Self-reported dietary intakes of vitamin D and calcium before and during $\mathrm{BCT}$ were determined using a fulllength, quantitative food frequency questionnaire (FFQ) (Block 2005 FFQ; NutritionQuest, Berkeley, CA). The FFQ was administered at baseline and wk 9 to estimate usual dietary intake from all food groups over the 3 mo prior to beginning training and during the 10-wk training course. Mean daily intakes of vitamin D and calcium were calculated from the USDA Food and Nutrient Database for Dietary Studies v. 1.0. Dietary supplements are not permitted during BCT.

\section{Statistical analysis}

Statistical analyses were performed using the Statistical Package for the Social Sciences v. 18.0 (SPSS Inc., Chicago, IL). Descriptive statistics are presented as mean \pm SEM. Normality was assessed using the KolmogorovSmirnov test. Race was treated as a dichotomus variable (white $(n=45)$ or non-white $(n=26))$. Mixed models repeated measures ANOVA with race and time included as fixed variables, and participant treated as a random variable, was used to assess main effects of time and race as well as time-by-race interactions. Akaike's information criteria were used to determine appropriate covariance structures. When a significant time-by-race interaction was observed, all possible t-tests with Bonferroni corrections were used to identify differences within and between groups. Log transformed variables were used in mixed models repeated measures ANOVA for variables that did not follow a normal distribution. Pearson's or Spearman's rank correlation were used as appropriate to test for associations between 25(OH)D levels and markers of inflammation (hsCRP and IL-6) and measures of body composition (body mass index (BMI) and body fat percentage). Mean daily intakes of vitamin $\mathrm{D}$ and calcium were compared to the US recommended dietary allowance (RDA) to compare experimental observations and population recommendations.

\section{Results}

Vitamin D status, PTH, and bone turnover

Serum $25(\mathrm{OH}) \mathrm{D}$ levels during BCT decreased $8 \%$ in whites but increased $21 \%$ in non-whites ( $P$-interaction < 0.05 , Table 2). At all time points, serum 25(OH)D levels were lower in non-whites than whites ( $P$-interaction < 0.05). Group mean PTH increased within 3 weeks, and then remained elevated for the duration of BCT (P-effect $<0.05$, Table 2). Mean PTH levels were greater in non-whites than whites $(P$-effect $<0.05)$.

Markers of bone formation, BAP and PINP, and bone resorption, TRAP and CTx, increased ( $P$-effect $<0.05$, Table 3) during BCT. There was no differential effect of race on markers of either bone formation or resorption.

\section{Anthropometrics and associations with vitamin D Status}

No significant correlations were noted between $25(\mathrm{OH})$ $\mathrm{D}$ levels or biomarkers of inflammation at either baseline or wk 9 (data not shown). Similarly, no significant correlations between 25(OH)D levels and body fat percentage or BMI were documented at baseline in the total study population. In non-whites, however, there was a positive

Table 2 Longitudinal changes in serum 25(OH)D and PTH levels in female Soldiers during BCT*

\begin{tabular}{|c|c|c|c|c|c|}
\hline & Baseline & Wk 3 & Wk 6 & Wk 9 & Effect \\
\hline $25(\mathrm{OH}) \mathrm{D}, \mathrm{nmol} / \mathrm{L}$ & & & & & $T \times R$ \\
\hline Group $(n=71)$ & $64.1 \pm 3.8$ & $60.4 \pm 2.9$ & $60.7 \pm 2.6$ & $63.2 \pm 2.6$ & \\
\hline White $(n=45)$ & $77.0 \pm 3.5$ & $70.6 \pm 3.5+$ & $68.6 \pm 3.5+$ & $70.5 \pm 3.5$ & \\
\hline Non-white $(n=26)$ & $41.7 \pm 4.6 \S$ & $42.6 \pm 4.6 \S$ & $47.8 \pm 4.6 \S$ & $50.6 \pm 4.6 \pm \$$ & \\
\hline PTH, pg/mL & & & & & $\mathrm{T}, \mathrm{R}$ \\
\hline Group $(n=71)$ & $32.7 \pm 1.7$ & $40.0 \pm 1.7 \dagger$ & $43.8 \pm 1.8 \dagger$ & $42.3 \pm 2.2 \dagger$ & \\
\hline White $(n=45)$ & $31.9 \pm 2.3$ & $36.7 \pm 2.3$ & $39.7 \pm 2.3$ & $38.6 \pm 2.3$ & \\
\hline Non-white $(n=26)$ & $34.0 \pm 3.0$ & $45.7 \pm 3.1$ & $50.7 \pm 3.0$ & $48.8 \pm 3.0$ & \\
\hline
\end{tabular}

*Mean \pm SEM; † Different from baseline $(P<0.05)$; Different from week 3 $(P<0.05)$; §Different from white, $(P<0.05) ; T$, main effect of time $(P<0.05) ; R$, main effect of race $(P<0.05)$; $T \times R$, time-by-race interaction $(P<0.05)$. 
Table 3 Longitudinal changes in bone biomarkers in female Soldiers during BCT*

\begin{tabular}{lccccc}
\hline \multicolumn{7}{c}{ Baseline } & Wk $\mathbf{3}$ & Wk $\mathbf{6}$ & Wk $\mathbf{9}$ & Effect \\
\hline Bone Absorption Biomarkers & & & & \\
\hline BAP, $\mu g / L$ & & & & & $T$ \\
\hline Group $(n=71)$ & $27.6 \pm 1.6$ & $36.6 \pm 1.9^{\dagger}$ & $39.1 \pm 1.9^{\dagger}$ & $38.8 \pm 2.0^{\dagger}$ & \\
\hline White $(n=45)$ & $26.2 \pm 2.3$ & $33.9 \pm 2.4$ & $37.1 \pm 2.3$ & $36.9 \pm 2.3$ & \\
\hline Non-white $(n=26)$ & $29.9 \pm 3.0$ & $41.1 \pm 3.1$ & $42.9 \pm 3.1$ & $42.0 \pm 3.0$ & \\
\hline PINP, $\mu g / L$ & & & & & $T$ \\
\hline Group $(n=71)$ & $62.4 \pm 3.7$ & $75.1 \pm 3.8+$ & $78.7 \pm 3.8+$ & $78.7 \pm 3.7 \dagger$ & \\
\hline White $(n=45)$ & $62.9 \pm 4.5$ & $72.5 \pm 4.6$ & $75.1 \pm 4.5$ & $77.7 \pm 4.5$ & \\
\hline Non-white $(n=26)$ & $61.9 \pm 5.9$ & $77.7 \pm 6.0$ & $82.4 \pm 6.0$ & $79.8 \pm 5.9$ & \\
\hline Bone Resorption Biomarkers & & & & \\
\hline TRAP, $U / L$ & & & & & $T$ \\
\hline Group $(n=71)$ & $4.3 \pm 0.2$ & $4.6 \pm 0.2$ & $4.8 \pm 0.2 \dagger$ & $5.0 \pm 0.2+, \pm$ & \\
\hline White $(n=45)$ & $4.2 \pm 0.2$ & $4.7 \pm 0.2$ & $4.8 \pm 0.2$ & $5.0 \pm 0.2$ & \\
\hline Non-white $(n=26)$ & $4.5 \pm 0.3$ & $4.4 \pm 0.3$ & $4.8 \pm 0.3$ & $5.0 \pm 0.3$ & \\
\hline CTx, $\mu g / L$ & & & & & $T$ \\
\hline Group $(n=71)$ & $1.1 \pm 0.1$ & $1.0 \pm 0.1$ & $1.2 \pm 0.1$ & $1.2 \pm 0.1 *$ & \\
\hline White $(n=45)$ & $1.2 \pm 0.1$ & $1.1 \pm 0.1$ & $1.1 \pm 0.1$ & $1.2 \pm 0.1$ & \\
\hline Non-white $(n=26)$ & $1.0 \pm 0.1$ & $1.0 \pm 0.1$ & $1.2 \pm 0.1$ & $1.1 \pm 0.1$ & \\
\hline
\end{tabular}

${ }^{*}$ Mean \pm SEM; †Different from baseline $(P<0.05) ;$ tDifferent from week 3 $(P<0.05) ; T$, main effect of time $(P<0.05)$.

correlation between body fat percentage and $25(\mathrm{OH}) \mathrm{D}$ levels at baseline $(0.46 ; P<0.05)$.

\section{Vitamin D and calcium intake}

In the total study population, reported mean daily intakes of vitamin $\mathrm{D}$ and calcium were below current RDA levels [22] both before and during BCT (Figure 1). Whites reported consuming more vitamin $\mathrm{D}$ during BCT when compared to non-whites $(P<0.05)$. Neither reported vitamin $\mathrm{D}$ nor calcium intake changed during the course of $\mathrm{BCT}$, regardless of race.

\section{Discussion}

The objective of this longitudinal, observational study was to assess the effects of military training on serum 25 $(\mathrm{OH}) \mathrm{D}, \mathrm{PTH}$ levels, bone turnover, and vitamin $\mathrm{D}$ and calcium intake in female Soldiers during BCT. The major finding was a differential response of serum 25 $(\mathrm{OH}) \mathrm{D}$ during BCT: $25(\mathrm{OH}) \mathrm{D}$ levels declined in white volunteers, but increased in non-white volunteers. Serum 25(OH)D levels were greater in white volunteers than non-white volunteers throughout BCT. Additionally, military training resulted in significant increases in PTH and markers of both bone formation and resorption, regardless of race. Estimated dietary intakes of vitamin $\mathrm{D}$ and calcium did not meet current RDAs, either before or during BCT. These data confirm earlier findings demonstrating a decline in $25(\mathrm{OH}) \mathrm{D}$ levels in white

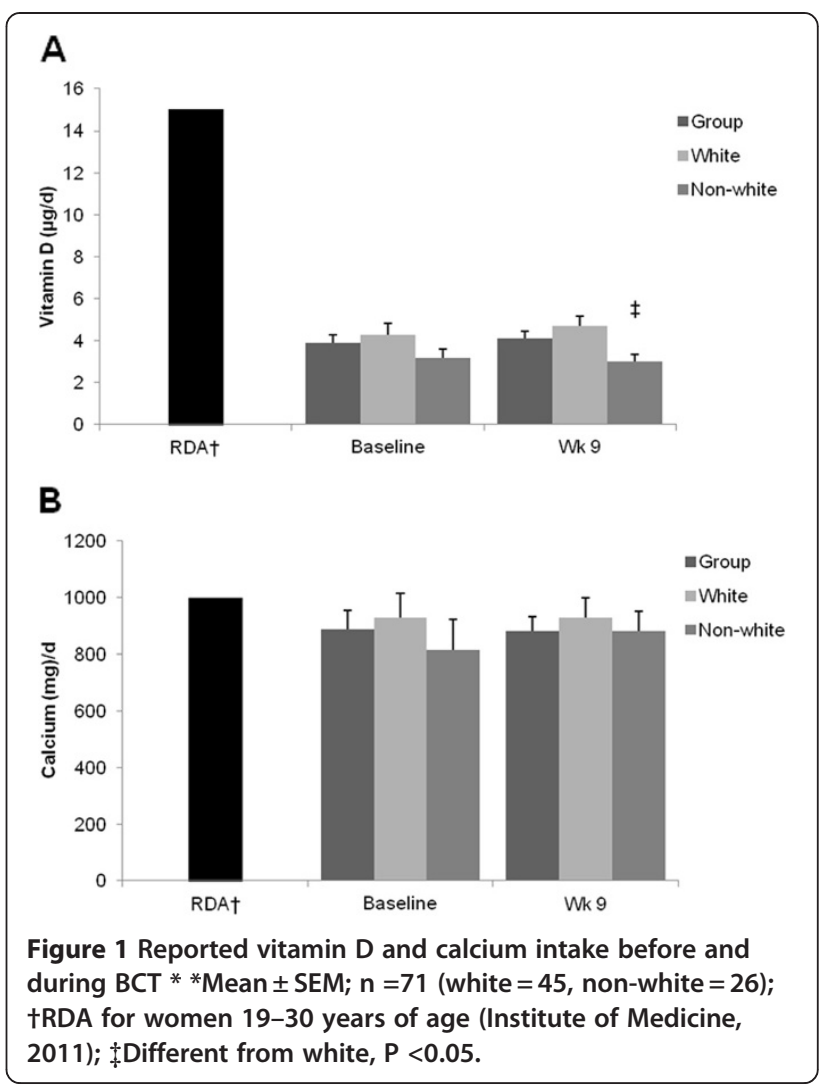

female Soldiers during military training [11], and indicate that non-white Soldiers respond differently. Further, the data suggest that military training results in increased bone turnover and may elevate calcium demands in female Soldiers, as demonstrated by the increases in PTH observed in this study cohort.

Suboptimal vitamin D status, coupled with the unaccustomed physical activities associated with military training, may have profound effects on bone health. During bone remodeling, resorption and formation are coupled; however, once resorption occurs, bone deposition may require up to 90 days for completion [23], and may induce temporary weaknesses at remodeling sites. Evans et al. [10] noted increases in both markers of bone formation and resorption during military training, similar to the findings of the present study. Similarly, studies assessing the effects of resistance-type training have documented increases in markers of bone formation, and a reduction in markers of bone resorption [24]. The increase in markers of both bone resorption and formation observed in the present study may indicate a mechanism to repair microdamage caused by repeated stress. If stress continues to affect bone, microdamage may further develop into stress fractures.

Stress fracture is of particular concern in military personnel, as up to $60 \%$ of female Soldiers that experience fracture may attrite from military training 
$[12,25,26]$. Studies reviewing stress fracture risk in military personnel indicate that a number of factors not affected by diet, such as female sex, menstrual status, contraceptive use, or polymorphisms in the vitamin D receptor, may be strong predictors of fracture risk $[8,12,25]$. Other factors, such as optimizing vitamin D status, may provide the opportunity to limit fracture risk through intervention. For example, Ruohola et al. [7] found that serum levels of $25(\mathrm{OH}) \mathrm{D}$ below the study population median $(76 \mathrm{nmol} / \mathrm{L})$ at the onset of military training was a significant risk factor for stress fracture in Finnish male military personnel. Burgi et al. [14] confirmed the relationship between $25(\mathrm{OH}) \mathrm{D}$ levels and stress fracture risk; in a case-control study with female Navy recruits it was determined that stress fracture risk was approximately double in volunteers who began training in the lowest quintile of $25(\mathrm{OH}) \mathrm{D}$ levels $(35 \mathrm{nmol} / \mathrm{L})$ as compared to those in the top quintile $(124 \mathrm{nmol} / \mathrm{L})$.

In a recent randomized, placebo-controlled intervention trial, Lappe et al. [12] found that daily provision of supplements containing $20 \mu \mathrm{g}$ of vitamin $\mathrm{D}$ and $2000 \mathrm{mg}$ of calcium reduced stress fracture incidence by up to $20 \%$ in female Navy recruits during training. Although this nutritional intervention appears beneficial for the prevention of stress fracture, the study did not include biochemical or functional assessments of serum 25(OH)D levels, PTH or bone health. As such, it is difficult to draw definitive conclusions regarding the mechanism by which supplementation with vitamin $D$ and calcium may have conferred protection. Comprehensive intervention trials including the collection of observational data regarding stress fracture occurrence coupled with biochemical and functional indicators of nutritional status and bone health will be required to determine the true efficacy of vitamin D and calcium interventions for the prevention of stress fracture in military personnel.

Our data indicate significant racial differences in serum 25(OH)D levels. For example, mean levels of serum 25(OH)D were greater in white volunteers as compared to non-white volunteers at the start of training. Further, serum 25(OH)D levels increased in nonwhites, but declined in white volunteers over the course of the training period. Racial differences in serum 25 $(\mathrm{OH}) \mathrm{D}$ levels have been described previously by our group [11] and others [15,27]. Paradoxically, although non-white populations tend to have lower mean serum $25(\mathrm{OH}) \mathrm{D}$ levels than white populations, non-white populations are at reduced risk for both osteoporotic $[28,29]$ and stress fractures [25]. Racial differences in the relationship between vitamin D status and bone health may be due to a number of factors, including differences in BMD [30,31] and bone geometry [30-32]. Other factors may include sensitivity to PTH. Skeletal resistance to PTH-stimulated bone resorption has been described in non-white populations [33], and may provide a mechanism by which non-white populations with suboptimal serum 25(OH)D levels retain BMD. In the present study, both serum 25(OH)D and PTH levels increased in nonwhite volunteers during training. In contrast, serum 25 $(\mathrm{OH}) \mathrm{D}$ levels declined in white volunteers during $\mathrm{BCT}$ as levels of PTH increased. This finding indicates racial differences in the relationship between serum 25(OH)D and PTH levels during military training, and warrants further scientific exploration, to include factors not assessed in the present study, such as the influence of physical activity and sunlight exposure.

Recent studies have used serum 25(OH)D cutoff values as indicators of suboptimal vitamin $\mathrm{D}$ status in populations. Some have recommended cutoff values of $\leq 75 \mathrm{nmol} / \mathrm{L}[34,35]$. Using this cutoff value to define inadequacy, $64 \%$ and $92 \%$ of white and non-white volunteers in this study completed BCT with suboptimal vitamin D levels, respectively. The most recent Institute of Medicine report on DRIs for calcium and vitamin D [22] is less conservative, suggesting that individuals may be at risk of vitamin $\mathrm{D}$ deficiency relative to bone health at serum $25(\mathrm{OH}) \mathrm{D}$ values $\leq 30 \mathrm{nmol} / \mathrm{L}$. Applying this cutoff value, no white volunteers and $8 \%$ of non-white volunteers completed BCT with suboptimal 25(OH)D levels. However, it is possible that the increased bone turnover experienced during BCT may affect the vitamin D requirement for this subpopulation. Data gleaned from this study and others [10] indicate increases in markers of both bone absorption and resorption during military training indicative of increased bone turnover. Increasing levels of PTH may suggest elevated calcium demand during training and may affect the vitamin D requirement in populations experiencing periods of rapid bone turnover.

Our data indicate that dietary consumption of vitamin $\mathrm{D}$ and calcium did not meet current recommendations [22] both before and during BCT. In fact, volunteers consumed less than one third of the current RDA for vitamin $\mathrm{D}$ both before and during training. Although sunlight exposure was not quantified during BCT, declines in serum 25(OH)D levels observed in white volunteers coupled with suboptimal serum 25(OH)D levels in non-white volunteers throughout the study indicate that strategies to improve dietary intake of vitamin $\mathrm{D}$ and calcium during military training may be needed to improve vitamin D status. Further, sweat mineral losses were not quantified in the present study. Estimates of mineral losses through sweat vary depending upon collection and assay techniques [36-38]. If significant calcium losses were to occur through sweating during military training, this could affect nutritional requirements and could affect bone health by stimulating PTH [39]. 


\section{Conclusion}

In summary, this longitudinal study determined vitamin D status during military training in females, to include interactions between vitamin D status and race. Serum $25(\mathrm{OH}) \mathrm{D}$ levels declined in white volunteers, and were lower in non-white volunteers as compared to white volunteers at all timepoints. Increases in PTH and indicators of bone turnover were observed during military training. Our findings indicate that efforts to improve the dining environment during military training should emphasize the consumption of foods containing vitamin $\mathrm{D}$ and calcium, as the cohort of Soldiers participating in the present study did not meet current recommended intakes for either nutrient. Strengths of the study included the longitudinal design in an environment free of dietary supplements and other factors that may have affected the carefully controlled collection of dietary status and intake data. Weaknesses include the lack of functional data regarding bone health and injury outcomes and a lack of data quantifying sun exposure. Future studies should determine whether the increased PTH and bone turnover observed during military training affect the vitamin $\mathrm{D}$ requirement, and whether vitamin $\mathrm{D}$ and calcium supplementation may be prudent for the prevention of injury, to include stress fracture.

\section{Competing interest}

$L L$, JPK, JCR, SJC, KWW, AJY, and JPM, no conflicts of interest.

\section{Authors' contributions}

JPM and JPK designed research; JPK, SJC, KWW, and JPM conducted research; JCR processed biological samples; LJL and JPK conducted statistical analysis; LJL, AJY and JPM wrote the paper; JPM had primary responsibility for final content. All authors read and approved the final manuscript.

\section{Acknowledgements}

We acknowledge the Soldier volunteers that participated in this study and the Command staff at Fort Jackson, SC, who provided access to potential volunteers. Research supported by the US Army Medical Research and Material Command. The opinions or assertions contained herein are the private views of the authors and are not to be construed as official or as reflecting the views of the Army or the Department of Defense. Any citations of commercial organizations and trade names in this report do not constitute an official Department of the Army endorsement of approval of the products or services of these organizations.

\section{Author details}

${ }^{1}$ Military Nutrition Division, United States Army Research Institute of Environmental Medicine, Natick, MA 01760, USA. ²Pennington Biomedical Research Center, Louisiana State University System, Baton Rouge, LA 70808, USA. ${ }^{3}$ Directorate of Basic Combat Training, Fort Jackson, SC 29207, USA.

Received: 2 April 2012 Accepted: 24 July 2012

Published: 6 August 2012

\section{References}

1. DeLuca HF: Overview of general physiologic features and functions of vitamin D. Am J Clin Nutr 2004, 80(Suppl):1689S-1696S.

2. Holick MF: Sunlight and vitamin D for bone health and prevention of autoimmune diseases, cancers, and cardiovascular disease. Am J Clin Nutr 2004, 80(Suppl):1678S-1688S.

3. Heaney RP: Vitamin D and calcium interactions: functional outcomes. Am J Clin Nutr 2008, 88(Suppl):541S-544S.
4. Adams JS, Hewison M: Update in vitamin D. J Clin Endocrinol Metab 2010, 95:471-478.

5. Foo LH, Zhang Q, Zhu K, Ma G, Hu X, Greenfield H, Fraser DR: Low vitamin $D$ status has an adverse influence on bone mass, bone turnover, and muscle strength in chinese adolescent girls. J Nutr 2009, 139:1002-1007.

6. Craney A, Weiler HA, O'Donnell S, Puil L: Summary of evidence-based review on vitamin $D$ efficacy and safety in relation to bone health. Am J Clin Nutr 2008, 88(Suppl):513S-519S.

7. Ruohola JP, Laakksi I, Ylikomi T, Haatja R, Mattila VM, Sahi T, Tuohimaa P, Pihlajamaki $\mathrm{H}$ : Association between serum $25(\mathrm{OH}) \mathrm{D}$ concentrations and bone stress fractures in Finnish young men. J Bone Miner Res 2006 21:1483-1488.

8. McClung JP, Karl JP: Vitamin D and stress fracture: the contribution of vitamin D receptor gene polymorphisms. Nut Rev 2010, 68:365-369.

9. Wentz L, Pei-Yang L, Haymes $E$, llich JZ: Females have greater incidence of stress fractures than males in both military and athletic populations: $A$ systematic review. Mil Med 2011, 176:420-430.

10. Evans RK, Antczak AJ, Lester M, Yanovich R, Israeli E, Moran DS: Effects of a 4-month recruit training program on markers of bone metabolism. Med Sci Sports Exerc 2008, 1(Suppl):660S-670S.

11. Andersen NE, Karl JP, Cable SJ, Williams KW, Rood JC, Young AJ, Lieberman HR, McClung JP: Vitamin D status in female military personnel during combat training. J Int Soc Sports Nutr 2010, 7:38.

12. Lappe J, Cullen D, Haynatzki G, Recker R, Ahlf R, Thompson K: Calcium and vitamin $D$ supplementation decreases incidence of stress fractures in female Navy recruits. J Bone Miner Res 2008, 5:741-749.

13. Jones BH, Canham-Chervak M, Canada S, Mitchener TA, Moore S: Medical surveillance of injuries in the US military: descriptive epidemiology and recommendations for improvement. Am J Prev Med 2010, 38:42S-60S.

14. Burgi AA, Gorham ED, Garland CF, Mohr SB, Garland FC, Zeng K, Thompson K, Lappe JM: High serum 25-hydroxyvitamin D is associated with a low incidence of stress fractures. J Bone Miner Res 2011, 26:2371-2377.

15. Harris SS, Dawson-Hughes B: Seasonal changes in plasma 25hydroxyvitamin D concentrations of young American black and white women. Am J Clin Nutr 1998, 67:1232-1236.

16. Pasiakos SM, Karl JP, Lutz LJ, Andersen NE, Margolis LM, Rood JC, Cable SJ, Williams KW, Young AJ, McClung JP: Cardiometabolic risk in US Army recruits and the effects of basic combat training. PLoS One 2012, 7:e31222.

17. Knapik JJ, Canham-Chervak M, Hauret K, Laurin MJ, Hoedebecke E, Craig S, Montain SJ: Seasonal variations in injury rates during US Army Basic Combat Training. Ann Occup Hyg 2002, 46:15-23.

18. Knapik JJ, Darakjy S, Hauret KG, Canada S, Marin R, Jones BH: Ambulatory physical activity during United States Army basic combat training. Int J Sports Med 2007, 28:106-115.

19. Department of the Army: Nutrition Standards and Education. Washington, DC: National Academy Press; 2001. AR. 40-25.

20. Jackson AS, Polluck ML, Ward A: Generalized equations for predicting body density of women. Med Sci Sports Exer 1980, 12:175-181.

21. Heyward VH: Evaluation of body composition. Current issues. Sports Med 1996, 22:146-156.

22. Institute of Medicine: Dietary reference intakes for calcium and vitamin D. Washington, DC: National Academies Press; 2011.

23. Robling $A G$, Castillo $A B$, Turner $\mathrm{CH}$ : Biochemical and molecular regulation of bone remodeling. Annu Rev Biomed Eng 2006, 8:455-498.

24. Schroeder ET, Hawkins SA, Jaque SW: Musculoskeletal adaptations to 16 weeks of eccentric progressive resistance training in young women. J Strength Cond Res 2004, 18:227-235.

25. Jones BH, Thacker SB, Gilchrist J, Kimsey CD Jr: Sosin DM: Prevention of lower extremity stress fractures in athletes and soldiers: a systematic review. Epidemiol Rev 2002, 24:228-247.

26. Friedl KE, Evans RK, Moran DS: Stress fracture and military medical readiness: bridging basic and applied research. Med Sci Sports Exerc 2008, 11(Suppl):609S-622S

27. Harris SS: Vitamin D and African Americans. J Nutr 2006, 136:1126-1129.

28. Barrett JA, Baron JA, Karagas MR, Beach ML: Fracture risk in the U.S. medicare population. J Clin Epidemio/ 1999, 52:243-249.

29. Bohannon AD, Hanlon JT, Landerman R, Gold DT: Association of race and other potential risk factors with nonvertebral fractures in communitydwelling elderly women. Am J Epidemiol 1999, 149:1002-1009. 
30. Li JY, Specker BL, Ho ML, Tsang RC: Bone mineral content in black and white children 1 to 6 years of age. Early appearance of race and sex differences. Am J Dis Child 1989, 143:1346-1349.

31. Bell NH, Shary J, Stevens J, Garza M, Gordon L, Edwards J: Demonstration that bone mass is greater in black than in white children. $J$ Bone Miner Res 1991, 6:719-723.

32. Theobald TM, Cauley JA, Gluer CC, Bunker CH, Ukoli FA, Genant HK: Blackwhite differences in hip geometry. Study of osteoporotic fractures research group. Osteoporos Int 1998, 8:61-67.

33. Cosman F, Morgan DC, Nieves JW, Shen V, Luckey MM, Dempster DW, Lindsay R, Parisien M: Resistance to bone resorbing effects of PTH in black women. J Bone Miner Res 1997, 12:958-966.

34. Dawson-Hughes B, Heaney RP, Holick MF, Lips P, Meunier PJ, Vieth R: Estimates of optimal vitamin D status. Osteoporos Int 2005, 16:713-716.

35. Vieth R, Bischoff-Ferrari HA, Boucher BJ, Dawson-Hughes B, Garland CF, Heaney RP, Holick MF, Hollis BW, Lamberg-Allert C, McGrath JJ, Norman AW, Scragg R, Whiting SJ, Willett WC, Zittermann A: The urgent need to recommend an intake of vitamin D that is effective. Am J Clin Nutr 2007, 85:649-650.

36. Bullen $\mathrm{DB}$, OToole ML, Johnson KC: Calcium losses resulting from an acute bout of moderate intensity exercise. Int I Sport Nutr 1999, 9:275-284.

37. Montain SJ, Cheuvront SN, Lukaski HC: Sweat mineral-element responses during $7 \mathrm{~h}$ of exercise-heat stress. Int I Sport Nutr Exerc Metab 2007, 17:574-582.

38. Chinevere TD, Kenefick RW, Cheuvront SN, Lukaski HC, Sawka MN: Effect of heat acclimation on sweat minerals. Med Sci Sports Exerc 2008, 40:886-891.

39. Barry DW, Hansen KC, Van Pelt RE, Witten M, Wolfe P, Kohrt WM: Acute calcium ingestion attenuates exercise-induced disruption of calcium homeostasis. Med Sci Sports Exerc 2011, 43:617-623.

doi:10.1186/1550-2783-9-38

Cite this article as: Lutz et al: Vitamin D status, dietary intake, and bone turnover in female Soldiers during military training: a longitudinal study. Journal of the International Society of Sports Nutrition 2012 9:38.

\section{Submit your next manuscript to BioMed Central and take full advantage of:}

- Convenient online submission

- Thorough peer review

- No space constraints or color figure charges

- Immediate publication on acceptance

- Inclusion in PubMed, CAS, Scopus and Google Scholar

- Research which is freely available for redistribution 